\section{ROOTS AND TRIBUTES}

According to Spitzer, writing in this issue, Alvan R Feinstein "influenced the very meaning of clinical research. He eschewed the concept of the patient as merely the ultimate beneficiary of clinical research and closed the loop by demonstrating that the best clinical data were provided by the patient". Full circle, then, from clinical epidemiology to "the doctor, the patient and the illness".

Diagnostic research needs to find new ways of producing knowledge relevant to diagnostic decision making so that evidence based diagnosis can become more of a reality. Research on diagnosis has yet to achieve the standards of quality of that in therapeutics. Moreover, the results of diagnostic research are rarely well integrated into evidence based recommendations or clinical guidelines.

In this issue, the Journal of Epidemiology and Community Health publishes an exchange of opinions on the future development of diagnostic research. A paper by Dr Feinstein is the starting point for this debate, sadly the father of clinical epidemiology died while this issue was being prepared. We have supplemented Dr Feinstein's review of research on diagnostic tests with contributions from Professor Walter O Spitzer, Emeritus Professor of Epidemiology at McGill University and Emeritus Editor of the Journal of Clinical Epidemiology, who has provided a tribute to Alvan Feinstein's life and work. The Journal of Clinical Epidemiology has provided a photographic portrait that we publish in the Gallery with text by $\mathrm{J}$ Andre Knottnerus, co-editor of the Journal of Clinical Epidemiology with Alvan R Feinstein. We hope the ideas put forward by our contributors to the debate on the future challenges of diagnostic research give new insights that are helpful to development in this field.

See pages $322,323,328-341$

\section{This issue live} and online www.jech.com
Continuing the emphasis on the roots of public health, we carry a review in our Public Health Policy and Practice section on the origins and early history of the Society for Social Medicine in the UK and Ireland by John Pemberton, one of the postwar British fathers of the subject. Pemberton's contribution is complemented by one from Klim McPherson and Karen Dunnell, who take the opportunity not only of filling in details of the later period of the Society from 1977 to 1992, but also of bringing out some of the tensions in the longstanding debate over medical and non-medical public health that has held public health back in the United Kingdom. While this emphasis on social medicine in parts of the British Isles may seem parochial, the experience may be of interest and value to practitioners in other parts of the world, and we are also reminded of the contribution of the founders of the Society for Social Medicine to its sister organisation, the International Epidemiological Association.

\section{See pages $342-348$}

Also in Public Health Policy and Practice we have a research finding that may be reassuring, that highly active anti-retroviral treatment does not increase sexual risk behaviour among French HIV infected injecting drug users; perhaps predictable associations are found in the paper from Johns Hopkins on the relation between social class gradients and several domains of health and health profiles in adolescence, but the authors point to the sparseness of existing data on this subject group; and migrants from Finland to Sweden were found to have comparable overall mortality to that prevailing in Finland, adding another bite of understanding to migration studies.

See pages 349,362

After a stream of publications on the impact of cold conditions on health, we publish new work from the London School of Hygiene using a time series approach that demonstrates the impact of hot temperatures on death in London (above $19^{\circ} \mathrm{C}$ ), apparently with no lag period; and another British paper, this time from Bristol, confirms other findings that excess winter mortality was not associated with area deprivation or rurality.

\section{See pages 367,378}

An editorial republished from Archives of Disease in Childhood reminds us of the complexity of social influences on birth weight, and underlines the policy message that change is necessary on a broad front over a protracted period to do something about this important determinant of social inequalities in health-smoking cessation and stress reduction may have some effect in the short-term, but they are scratching the surface of what is really needed.

\section{See page 326}

In a full issue, we also carry a report from Norway on trends in health inequalities by educational level, from the Framingham Nutrition Studies on the internal validity of dietary pattern analysis, on the relation between maternal work, ambulatory blood pressure, and hypertension in pregnancy (there is one), and the fascinating finding from Spain that British drivers seem to be more at risk of being involved in road traffic accidents than the Spanish in Spain (who presumably are accustomed to local norms of driving).

See pages $375,381,389,394$

Our correspondence column carries an interesting discussion about decreasing AIDS mortality rates from two groups of researchers in this field.

See page 399

On a final note, the editors are disappointed so far at the request to authors to identify policy implications of research findings. Please try harder! 